\title{
What Parents Believe about Antibiotics
}

\author{
Michael Jobansen, MD, MS, Associate Editor \\ Ann Fam Med 2017;15(2):iii. https://doi.org/10.1370/afm.2055.
}

$\mathrm{T}$ The Annals of Family Medicine encourages readers to develop a learning community of those seeking to improve health care and health through enhanced primary care. You can participate by conducting a RADICAL journal club and sharing the results in the Annals online discussion. RADICAL is an acronym for Read, Ask, Discuss, Inquire, Collaborate, Act, and Learn. "Radical" also indicates the need to engage diverse participants in thinking critically about important issues affecting primary care and acting on those discussions. ${ }^{1}$

\section{HOW IT WORKS}

In each issue, the Annals selects an article and provides discussion tips and questions. We encourage you to take a RADICAL approach to these materials and post a summary of your conversation in our online discussion. (Open the article online and click on "TRACK Comments: Submit a response.") You can find discussion questions and more information at: http://www. AnnFamMed.org/site/AJC/.

\section{CURRENT SELECTION}

\section{Article for Discussion}

Coexter PD, Del Mar C, Hoffman TC. Parents' expectations and experiences of antibiotics for acute respiratory infections in primary care. Ann Fam Med. 2017;15(2):149-153.

\section{Discussion Tips}

Surveys are an important tool that can help researchers explain phenomena as well as gain a better grasp on current practice. This survey investigates parents' perceptions about treatment of acute respiratory tract infections that could increase our knowledge about tackling the challenging problem of antibiotic overuse in children.

\section{Discussion Questions}

- What question is asked by this study and why does it matter?

- How does this study advance beyond previous research and clinical practice on this topic?

- How strong is the study design for answering the question? How does the response rate affect your interpretation of the validity of the findings?

- How were individuals selected or excluded to participate? How could this have introduced bias into the study?

- What are the main study findings?

- The authors asked about cough, sore throat, and acute otitis media. What do you think about the differences in the responses between the 3 conditions?

- Do you feel the individuals that were surveyed were similar to the parents in your practice?

- A large majority of parents endorsed a desire to have a say in their children's treatment. Despite this, parents reported a much lower rate of shared decision making. Do think this is consistent with practice in your clinic?

- How could you increase the use of shared decision making in your practice? How might this article and other articles inform you about how to approach this? $?^{2-3}$

- In what other ways might this study change your practice? Policy?

-What researchable questions remain?

\section{References}

1. Stange KC, Miller WL, McLellan LA, et al. Annals Journal Club: It's time to get RADICAL. Ann Fam Med. 2006;4(3):196-197. http:// annfammed.org/cgi/content/full/4/3/196.

2. Coexter PD, Del Mar C, Hoffman TC. Parents' expectations and experiences of antibiotics for acute respiratory infections in primary care. Ann Fam Med. 2017;15(2):149-154.

3. Riggs KR, Ubel PA, Saloner B. Can appealing to patient altruism reduce overuse of health care services? An experimental survey. J Gen Intern Med. 2017 Feb 2. [Epub ahead of print]. 